\title{
The impact of the COVID-19 pandemic on oral health inequalities and access to oral healthcare in England
}

\author{
Michelle Stennett*1 and Georgios Tsakos ${ }^{1}$
}

\section{Key points}

People living in more deprived areas have fared worse than people living in less deprived areas, in terms of uptake of NHS primary dental care following the resumption of services in June 2020.
The cessation of oral health improvement programmes in the community and the dramatic decline of hospital dental services due to the COVID-19 pandemic have also primarily impacted the more socially disadvantaged groups, further widening inequalities.
Addressing the widened oral health inequalities requires long-term investment in oral health, prioritising public health programmes and supporting access to services.

\begin{abstract}
While the impact of the coronavirus disease (COVID-19) pandemic on health inequalities is documented, oral health has been absent from this discussion. This commentary highlights the potential impacts of the COVID-19 pandemic on oral health inequalities in England in February 2021. It includes a literature review, Public Health England and Kantar Worldpanel sales data on health behaviours and analysis of NHS dental services data. Purchasing data indicate, except for smoking, increases in health-compromising behaviours. Since the resumption of dental services, NHS general dental service use modestly recovered among adults but not children by October 2020. There are clear inequalities among children and older adults, with more deprived groups having lower uptake of dental service use than more affluent groups. Oral cancer referrals and hospital admissions for tooth extractions in children dramatically declined, with the latter primarily affecting children in more deprived areas. Many oral health programmes in schools and care homes were disrupted or suspended throughout this period. All these indicate that oral health inequalities have widened due to the COVID-19 pandemic. An oral health plan of action requires prioritising long-term investment in public health programmes and transforming commissioning pathways to support those with the greatest needs to access oral healthcare services.
\end{abstract}

\section{Introduction}

Inequalities in oral health have been widely documented in the UK and are evident across the social spectrum and life course, largely reflecting the socio-economic inequalities in general health. ${ }^{1,2,3,4,5}$ Furthermore, marginalised and vulnerable groups (such as homeless people and care home residents) present the cliffedge of inequality, having excessively poorer oral health outcomes, often coupled with considerable barriers and limited access to oral healthcare compared to the general population. ${ }^{6}$

In the last 18 months, the emergence of COVID-19 has led to unprecedented

'Department of Epidemiology and Public Health, University College London, 1-19 Torrington Place, London, WC1E

7HB, UK.

${ }^{*}$ Correspondence to: Michelle Stennett

Email address: michelle.stennett@ucl.ac.uk

Refereed Paper.

Accepted 13 June 2021

https://doi.org/10.1038/s41415-021-3718-0 economic and public health crises globally. ${ }^{7,8}$ The UK has seen one of the highest mortality rates per head of population in the world ${ }^{9}$ and has experienced a significant economic contraction, having implications for job security, income and consequently, health. ${ }^{10,11}$ In addition, contrary to suggestions that COVID-19 is a 'socially neutral disease', there is clear evidence that COVID-19 has disproportionately affected socially disadvantaged groups. ${ }^{12,13}$ Therefore, it is postulated that the COVID-19 pandemic will have a worsening long-term effect on health inequalities in the UK, further to an existing backdrop of widening health inequalities since 2010. ${ }^{14,15}$

Oral health inequalities have been largely absent from this discussion. This is despite the fact that oral conditions present a global public health problem and are socially patterned and highly prevalent with a considerable burden on individuals and societies, while, at the same time, are largely preventable. ${ }^{16,17,18}$ This commentary aims to highlight and discuss the potential impact of the COVID-19 pandemic on oral health inequalities in England.

As there is currently no direct evidence of the impact of the COVID-19 pandemic on oral health outcomes, we looked at the potential impact of the COVID-19 pandemic on key health behaviours, as well as access to and provision of oral healthcare services, including preventive programmes, as they are expected to influence inequalities in oral health. We reviewed the literature and used Public Health England (PHE) data, Kantar Worldpanel sales data on health behaviours and NHS dental service data.

\section{The COVID-19 pandemic and oral health behaviours}

High sugar consumption, poor oral hygiene, smoking and alcohol consumption are all known risk factors for oral diseases. ${ }^{19,20,21,22}$ Health-compromising behaviours cluster in lower socio-economic groups $s^{23,24}$ and present 
Fig. 1 Percentage change in average volume product sales over four weeks in 2020 compared to the same weeks in 2019 (weeks ending 22 March 2020 and 12 July 2020) by social class. AB = higher and intermediate managerial, administrative and professional workers. C1 = supervisory, clerical and junior managerial, administrative and professional workers. $C 2=$ skilled manual workers. $D=$ semi-skilled and unskilled manual workers. E = people on long-term state benefits, casual and lowest grade workers, unemployed with state benefits (including pension) only. Data source: Public Health England. Wider impacts of COVID-19 on health analysis of Kantar Worldpanel data $2020^{30}$

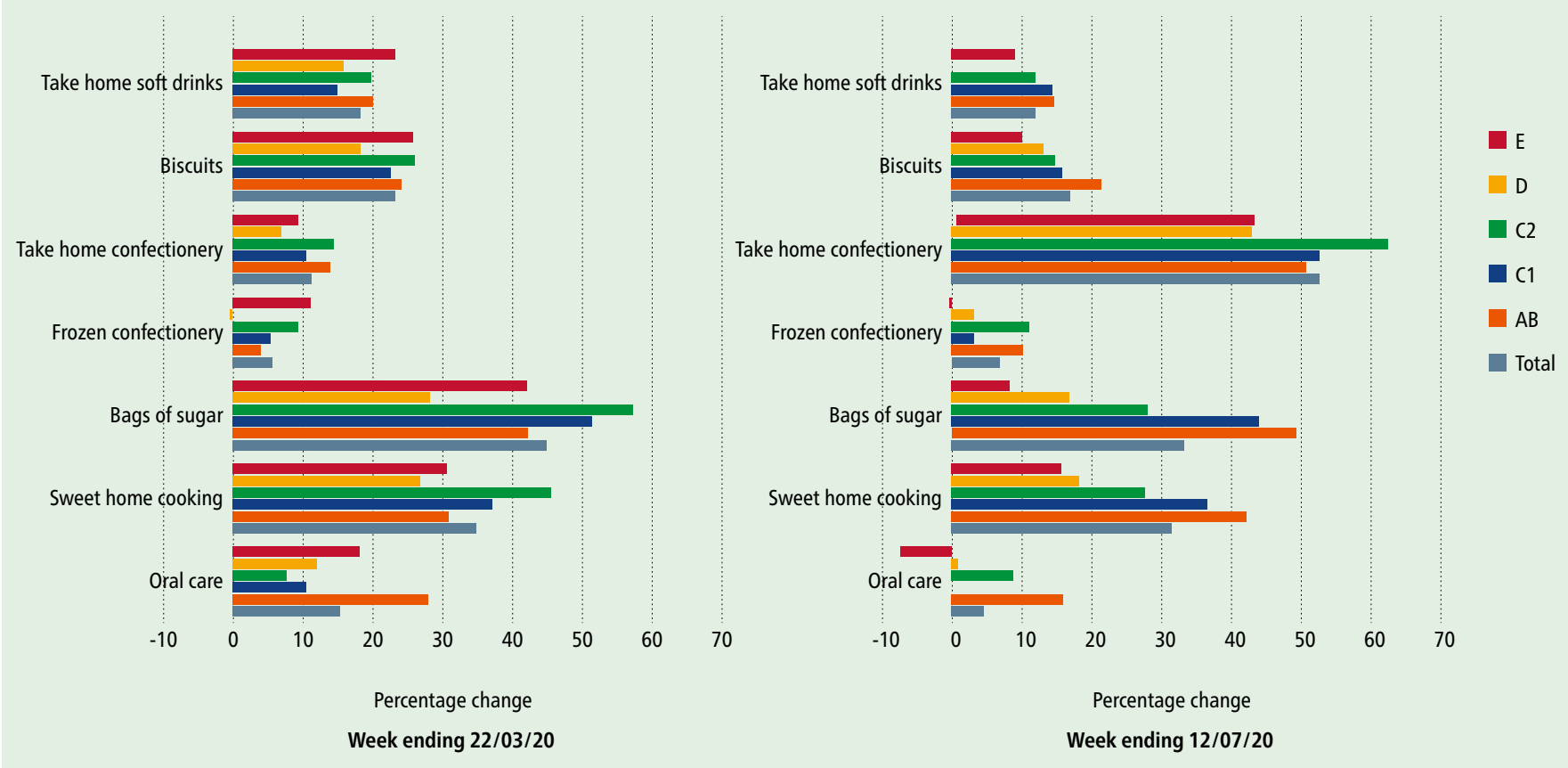

a pathway towards oral health inequalities. ${ }^{25,26}$ There is generally limited data on the impact of the COVID-19 pandemic on oral health behaviours. However, some relevant information can be extracted by looking at changes in purchasing patterns, though clearly this is not a direct reflection of actual behavioural practices.

\section{Diet}

Prior to the COVID-19 pandemic, few people met dietary recommendations and although those from higher income groups were nearer to achieving some recommendations, diets did not meet recommendations across all income groups. ${ }^{27}$ Compared to the corresponding weeks in 2019, there were increases in the reported purchase of confectionery, biscuits and sweet home cooking (all foods 'rich' in free sugars) among adults in the weeks before the initial lockdown (March 2020) and also later in June/July 2020 (Fig. 1). High intakes of sugars are a major risk factor for dental caries and can also lead to excess calorie consumption, thereby increasing the risk of becoming overweight or obese. ${ }^{28}$ Both of these are more prevalent in deprived groups. ${ }^{29}$

\section{Oral hygiene}

There was some variation in oral care product purchases around the time of the initial lockdown. Compared to the corresponding weeks in 2019, there was a large increase in oral care product purchases across all social classes, but more so for the higher social classes, just before the initial lockdown in March 2020. However, the pattern changed by June/July 2020, when the increases were more modest for the higher social classes and there was even a decrease in oral product purchases for the lowest social class (Fig. 1).

\section{Smoking}

There were no significant changes in the prevalence of smoking according to socioeconomic position over the course of the initial lockdown, but increases in attempts to quit smoking and in cessation rates among smokers were noted in both managerial and skilled manual workers. ${ }^{30}$ There is currently not enough evidence to understand whether these changes may affect the longerterm prevalence of smoking between the different socio-economic groups and thereby potentially further influence oral health inequalities.

\section{Alcohol consumption}

A PHE evidence review in 2016 found that the harmful effects of alcohol were greatest in deprived groups. ${ }^{31}$ Data suggest that alcohol sales/consumption increased overall during 2020. ${ }^{32}$ Kantar Worldpanel sales data analyses measuring alcohol purchasing in off-trade settings (such as supermarkets) also suggest that the volume of alcohol sales increased by $36 \%$ between March and June 2020 . This may be expected, since on-trade settings (for example, pubs) were closed for those four months. However, alcohol duty receipts (which include on- and off-trade sales) indicate that people consumed more alcohol than in previous years. Surveys suggest a polarisation in self-reported drinking patterns, with similar proportions reporting drinking more and less alcohol than before the first national lockdown. ${ }^{32}$ Importantly, evidence suggests that the heaviest $20 \%$ of buyers of alcohol before the COVID-19 pandemic accounted for $45 \%$ of the total increase in sales following the pandemic. ${ }^{32}$ Put together, data from sales and surveys suggest that despite the closure of the on trade at the beginning of the COVID19 pandemic, alcohol sales increased and this increase was driven by heavy consumers of 
alcohol. Consequently, this high-risk group of heavy drinkers is now, following the lockdown, even more likely to experience alcohol-related harm with implications for oral health, particularly for oral cancer.

\section{The COVID-19 pandemic and oral healthcare services}

Access to primary dental care

With the initial lockdown in March 2020, all routine and non-urgent dental care ceased. Instead, urgent dental care centres were established to provide care for people who could not be managed remotely with advice, analgesia or antibiotics. ${ }^{33}$ NHS general dental service data for England reflect these changes and demonstrate a dramatic decline (98\%) in dental services used by children, adults and older adults in this initial lockdown period (Fig. 2). With limitations in access to routine services, there were reports regarding rises in dental infections necessitating emergency hospital treatment ${ }^{34}$ and increased episodes of 'do it yourself' dentistry. ${ }^{35}$

In England, non-urgent dental care services resumed on 8 June 2020, though the resumption was gradual, as not all practices were ready and appropriately equipped to do so immediately. Inability to carry out aerosol generating procedures (AGPs) due to a lack of personal protective equipment and practical arrangements of care provision due to surgery down-time following AGPs affected care provision. Reports indicate continued difficulties in access to both urgent and routine dental care, with a Healthwatch report suggesting that in some mixed practices, private dental care was prioritised over NHS provision. ${ }^{36}$ NHS data highlighted some increase in general dental service activity following the resumption of dental services, though the activity was still considerably lower compared to the previous year, with $67 \%$ fewer people utilising services in October 2020 than in October 2019. The increase in NHS dental service activity happened more quickly and at a higher rate for adults than children (Fig. 2). Furthermore, there were clear inequalities in the uptake of dental services in this initial resumption period, particularly among children and older adults, with $10 \%$ more children and older adults in the least deprived areas of England utilising services in October 2020, compared to those in the most deprived areas (Fig. 3, online Supplementary Figures 1 and 2). These inequalities reflect NHS dental care and

Fig. 2 Number of people accessing general dental services in England from January 2019 to October 2020 by age group and month. Data source: NHS Business Services Authority 2020

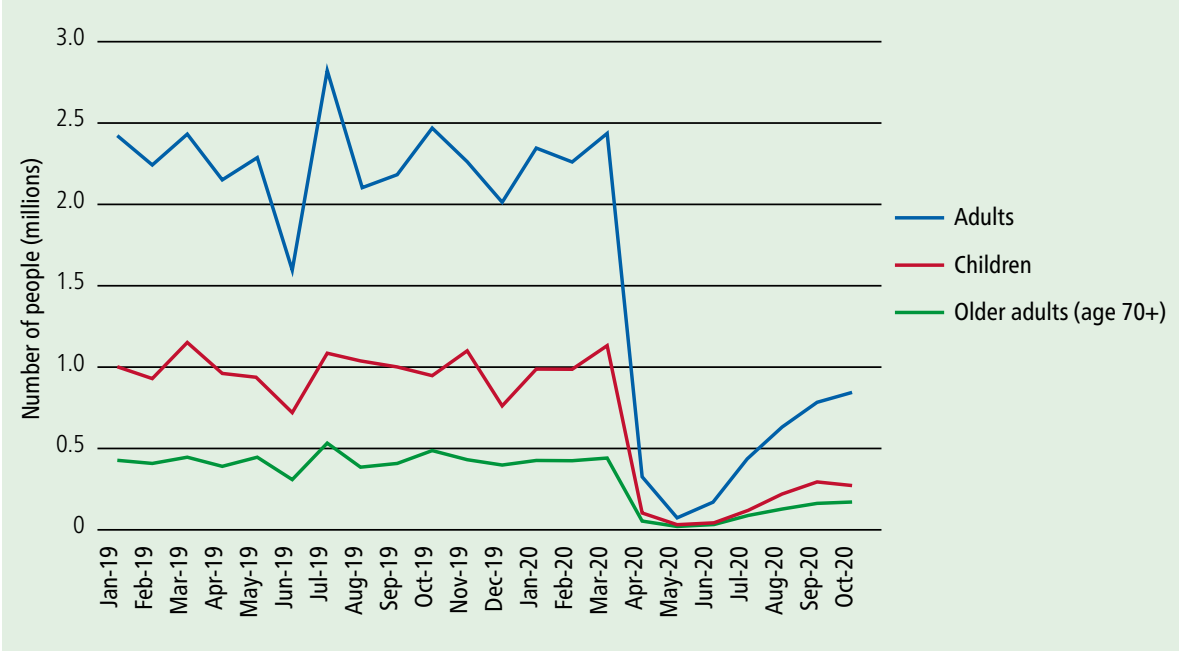

Fig. 3 Monthly percentage change in child access to NHS dental services 2020 vs 2019 by IMD 2015 national deprivation quintile. 5 = least deprived quintile, $1=$ most deprived quintile. Data source: NHS Business Services Authority 2020

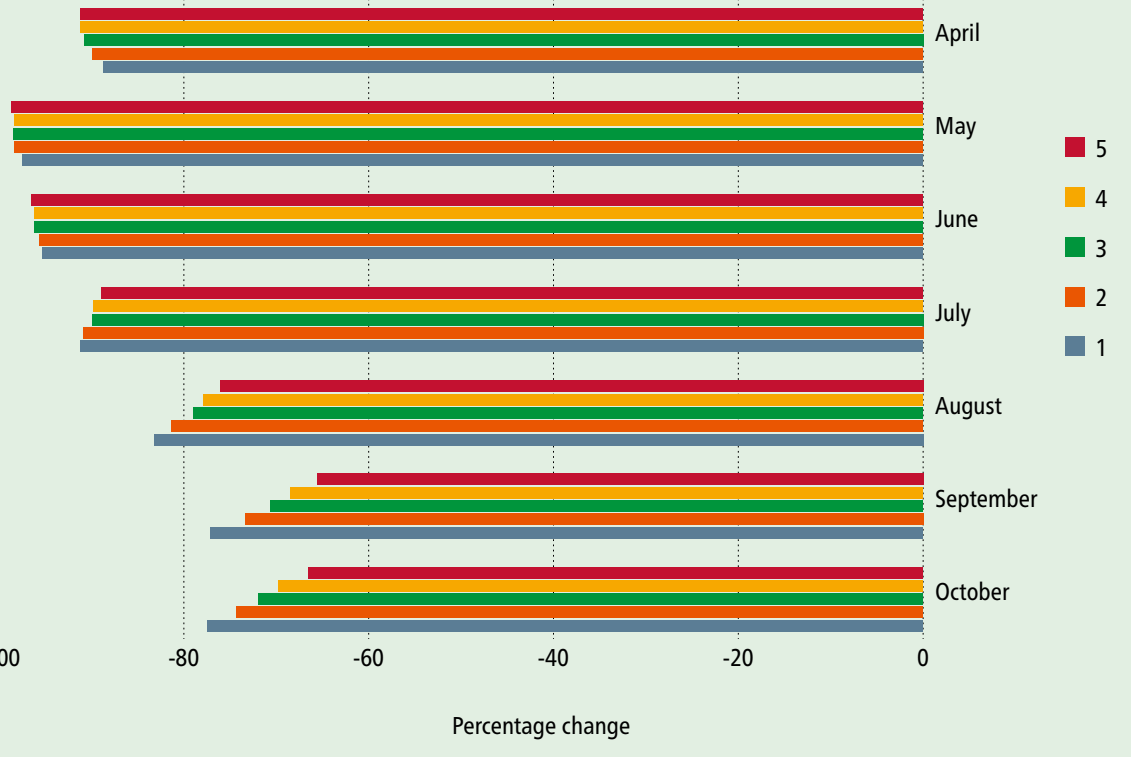

do not consider private provision.

\section{Access to secondary dental care}

Tooth extractions are the most common reason for hospital admissions among children aged 6-10 years old. ${ }^{37}$ Along with the cessation of routine dental services in March 2020, many hospitals throughout England also cancelled elective tooth extraction lists and comprehensive care lists in order to accommodate the anticipated increased capacity needed to treat COVID19 patients. ${ }^{38,39}$ The lower provision of these services also impacts people from vulnerable groups (for example, those with learning disabilities) who may require hospital services, often with general anaesthesia, for the provision of dental care.

For oral surgery hospital referrals, 75\% of patients were seen within the 18-week referral to treatment time limit in March 2020. By August 2020, this had fallen to 32\% of patients. ${ }^{40,41}$ In 0-19-year-olds, there was a $94 \%$ decrease in hospital episodes of dentalcaries-related tooth extractions in April 2020 compared with April 2019. ${ }^{37}$ Hospital 
Fig. 4 Hospital episodes of dental caries-related tooth extraction in 0-19-year-olds by deprivation quintile, rate per 100,000 population. Data source: Public Health England 2020

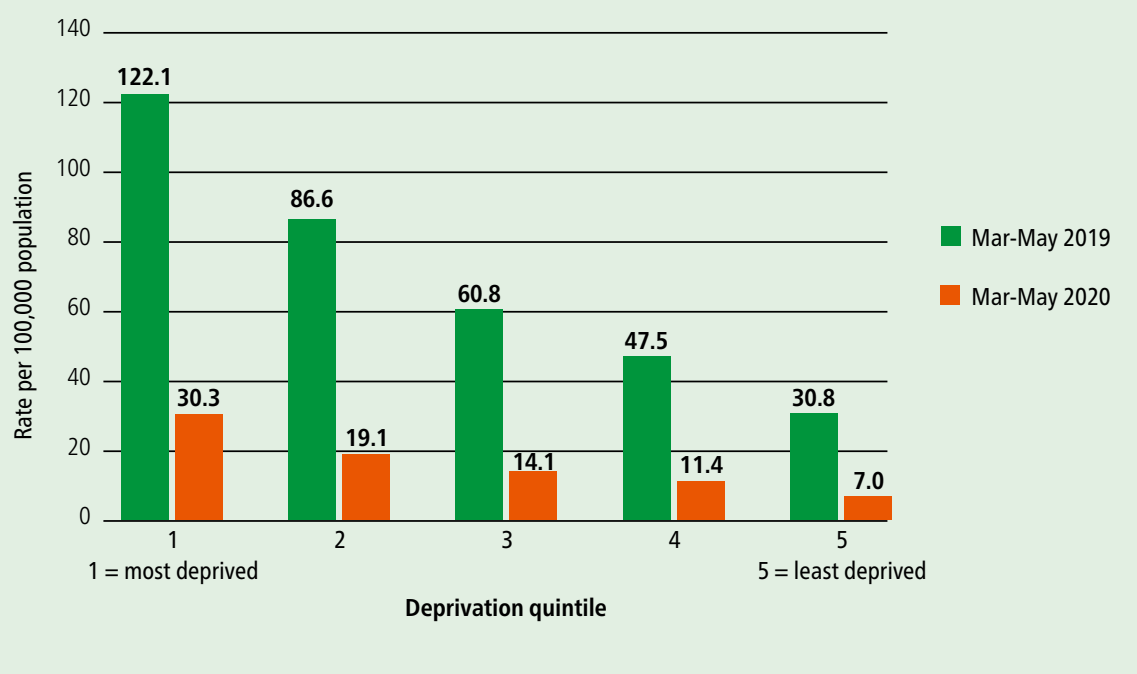

admissions for tooth extractions are strongly socially patterned with children living in more deprived areas being more likely to receive this care and have more teeth removed during an episode..$^{37,38}$ The reduction in hospital tooth extractions impacted, in terms of absolute numbers, more upon the deprived children, even though it was proportionately similar across socio-economic groups. For example, the rate of hospital tooth extraction episodes per 100,000 population dropped from 122 between March to May 2019 to 30 between March to May 2020 among the most deprived children (a difference of 92 per 100,000), while the respective figures among the least deprived were 31 and 7, a difference of 24 per 100,000 (Fig. 4).

Across England, re-establishment of services varied $^{42}$ with many hospital tooth extraction services for children seeing restricted numbers of cases. ${ }^{43}$ In many areas, this has resulted in longer waiting lists and therefore increased treatment needs and higher impact in terms of pain, sleepless nights and missing school. ${ }^{44}$ The exact impact of these developments remains to be quantified, but considering the aforementioned stark inequalities, the more deprived children and vulnerable adults will be primarily affected by the continuing lower levels of service provision.

\section{Oral cancer services}

In the UK, there are marked inequalities in rates of oral cancers, with higher incidence rates in more deprived and vulnerable groups. ${ }^{45,46}$ Dental examinations allow opportunistic screening for signs and symptoms of oral cancer, with early diagnosis having a profound impact on successful treatment and survival rates. With the cessation of routine dental examinations during the initial lockdown, there has been a substantial decrease in urgent referrals for suspected oral cancer. ${ }^{47,48}$ A reduction in referrals will have additional impacts on prompt treatment provision and referral waiting times. ${ }^{49}$ To put this into context, a modelling exercise predicted that a delay in oropharyngeal cancer diagnosis of up to three months can result in a $10 \%$ survival reduction over ten years. ${ }^{50}$

\section{Oral health improvement programmes}

Early years and school-supervised tooth brushing programmes in England ${ }^{51}$ have been affected by the COVID-19 pandemic. Such programmes are commissioned to support, primarily, children with poor oral health, through an increased level of provision in more deprived areas. With the closure of all schools and early years settings (except to the children of key workers) in March 2020, oral health programmes in England were suspended. This temporary suspension continued after primary schools welcomed back children in June 2020. Revised guidance in England allowed for the restarting of these programmes in the 2020-2021 academic year, as settings and commissioners felt appropriate. The break in provision and delay in re-establishment of oral health promotion programmes has long-term implications for the oral health of young children.

On the other end of the age spectrum, vulnerable adults in care homes have been hit particularly hard by COVID-19 with excessive mortality rates. ${ }^{52}$ In general, oral health improvement practices in care homes have been found to be poor and routine dental care, including access to domiciliary services, is also challenging. ${ }^{53}$ These issues have been further highlighted by the COVID-19 pandemic. Oral healthcare services and programmes in care homes ceased as oral health professionals and health promoters had limited access to care homes for a prolonged period. ${ }^{47,54}$ Within this context, the inclusion of oral health in the enhanced 'Health in care homes' framework ${ }^{55}$ is a positive development, as dental practices can be linked to care homes through primary care networks.

\section{Summary and implications for action}

The totality of the evidence presented above in terms of health behaviours, reduced access to services (particularly for the vulnerable) and cessation of oral health improvement programmes, indicate that the COVID-19 pandemic is likely to have a major impact on oral health and result in a widening of inequalities.

Dental care provision was dramatically reduced in the initial lockdown period and after resumption of services is still considerably lower than in the previous year, particularly among deprived children and older adults. It seems that less deprived groups are more able to navigate the changing architecture of NHS dental service provision than the more deprived. This is a serious concern, as the vulnerable, more deprived population groups have a greater reliance on the NHS for their dental care. ${ }^{56}$ Other important services (eg for oral cancer and secondary dental care) have also been severely affected, primarily impacting the lower socioeconomic and more vulnerable groups. In addition, many oral health improvement programmes have stopped. The impacts of the COVID-19 pandemic and lockdown are considerable, not only for patients and the population, but also for the oral healthcare workforce. Clinicians and their staff have had to deal with the initial closure of routine dental services, significant changes in care delivery and accessing personal protective equipment, at the same time as caring for staff and patients and balancing family life. While this commentary reflects on the situation up 
to February 2021, it should be acknowledged that oral health programmes and dental services are part of an ever-changing picture as we move through the different phases of the COVID-19 pandemic.

Within this context, it is crucial to consider a plan of action to address oral health inequalities as we deal with the COVID19 pandemic and move beyond/towards resumption of primary dental care services to pre-COVID-19 levels. It is important to re-align dental care provision and transform commissioning pathways to prioritise equity of access to oral health services. This is in line with the World Health Organisation emphasis of including oral health in the Universal Health Coverage compendium. ${ }^{57,58}$

However, the anticipated increased oral health burden and widened inequalities cannot be simply treated away or addressed through increased and more equitable provision of care. There is an urgent need to increase the reach of oral health improvement programmes that have evidence of effectiveness in reducing oral health inequalities, such as community water fluoridation and daily, supervised tooth brushing in early years settings. ${ }^{59,60}$ This highlights the need for programmes with emphasis on the more vulnerable groups - those whose 'voices' are often not heard. Addressing the broader social, environmental and commercial determinants of health and incorporating oral health within public health initiatives (for example, public health actions to reduce sugar consumption) is essential if we want to reduce oral health inequalities. This is even more of a priority in the current context of other widened inequalities due to the COVID-19 pandemic. The extensive disruption to the education of children within the UK may lead to long lasting, negative effects on educational outcomes, particularly for disadvantaged students with limited access to online resources. ${ }^{61}$ Moreover, the economic downturn initiated by the COVID-19 pandemic may result in decreased availability of jobs and is more likely to have greater impacts on the job prospects of people from lower socioeconomic backgrounds. ${ }^{61}$ These impacts on the broader social determinants, while not strictly within the scope of this commentary, are all likely to have far reaching implications for widened oral health inequalities that go well beyond the observed effects of the
COVID-19 pandemic on health behaviours and healthcare services.

\section{Conclusion}

There is a need to move away from years of disinvestment in public health. ${ }^{62,63}$ Prioritising public health programmes and supporting equitable access to services will help to build a fairer society following the damaging impacts of the COVID-19 pandemic. ${ }^{64}$ After all, good oral health contributes considerably to the health and quality of life of the population.

\section{Ethics declaration}

The authors declare no conflicts of interests.

\section{Author contributions}

Georgios Tsakos conceived the original manuscript.

Michelle Stennett and Georgios Tsakos drafted, edited and revised the manuscript. Both authors edited and approved the final text before submission for publication.

\section{Acknowledgements}

We thank the NHS Business Service Authority

for providing data in relation to the primary dental care services activity. Michelle Stennett acknowledges the support of the National Institute for Health Research through an NIHR In-Practice Fellowship (NIHR301037). The views expressed in this publication are those of the author(s) and not necessarily those of the NHS, the National Institute for Health Research or Public Health England.

\section{References}

1. Watt $R$, Sheiham $A$. Inequalities in oral health: A review of the evidence and recommendations for action. $\mathrm{Br}$ Dent J 1999; 187: 6-12.

2. Steele J, Shen J, Tsakos G et al. The interplay between socioeconomic inequalities and clinical oral health. J Dent Res 2015; 94: 19-26.

3. Guarnizo-Herreño C C, Watt R G, Fuller E et al. Socioeconomic position and subjective oral health: Findings for the adult population in England, Wales and Northern Ireland. BMC Public Health 2014; DOI: 10.1186/1471-2458-14-827.

4. Rouxel P, Chandola T. Socioeconomic and ethnic inequalities in oral health among children and adolescents living in England, Wales and Northern Ireland. Community Dent Oral Epidemiol 2018; 46: 426-434.

5. Delgado-Angulo E K, Mangal M, Bernabé E. Socioeconomic inequalities in adult oral health across different ethnic groups in England. Health Qual Life Outcomes 2019; DOI: 10.1186/ s12955-019-1156-3.

6. Watt R G, Venturelli R, Daly B. Understanding and tackling oral health inequalities in vulnerable adult populations: from the margins to the mainstream. $\mathrm{Br}$ Dent J 2019; 227: 49-54

7. Narain J P, Dawa N, Bhatia R. Health System Response to COVID-19 and Future Pandemics.J Health Manag 2020; 22: 138-45.

8. McKee, M, Stuckler D. If the world fails to protect the economy, COVID-19 will damage health not just now but also in the future. Nat Med 2020; 26, 640-642.
9. Our World In Data. Coronavirus (COVID-19) Deaths. 2021. Available at https://ourworldindata.org/coviddeaths? country=IND USA GBR CAN DEU FRA (accessed February 2021)

10. Office for National Statistics. Coronavirus and the impact on output in the UK economy: December 2020. 2021. Available at https://www.ons.gov. uk/economy/grossdomesticproductgdp/articles/ coronavirusandtheimpactonoutputintheukeconomy/ december2020 (accessed February 2021).

11. The Health Foundation. Will COVID-19 be a watershed moment for health inequalities? 2020. Available at https://www.health.org.uk/publications/long-reads/ will-covid-19-be-a-watershed-moment-for-healthinequalities (accessed February 2021)

12. Bambra C, Riordan R, Ford J, Matthews F. The COVID19 pandemic and health inequalities. J Epidemiol Community Health 2020; 74: 964-968.

13. Whitehead M, Taylor-Robinson D, Barr B. Poverty, health and covid-19. BMJ 2021; 372:n376. Available at: http://dx.doi.org/10.1136/bmj.n376. (accessed December 2021).

14. Marmot M. Society and the slow burn of inequality. Lancet 2020; 395: 1413-1414.

15. Institute of Health Equity. Health equity in England: The Marmot Review 10 years on. 2020. Available at https:// www.instituteofhealthequity.org/resources-reports/ marmot-review-10-years-on/the-marmot-review-10 years-on-full-report.pdf (accessed February 2021).

16. Peres M A, Macpherson L M D, Weyant R J et al. Oral diseases: a global public health challenge. Lancet 2019; 394: 249-260.

17. Marcenes W, Kassebaum N J, Bernabé E et al. Global Burden of Oral conditions in 1990-2010: A systematic analysis. J Dent Res 2013; 92: 592-597.

18. International Centre for Oral Health Inequalities Research and Policy. Social inequalities in oral health: from evidence to action. 2015. Available at https:// media.news.health.ufl.edu/misc/cod-oralhealth/docs/ posts_frontpage/Sociallnequalities.pdf (accessed February 2021)

19. Moynihan P J, Kelly S A M. Effect on Caries of restricting sugar intake: systematic review to inform WHO guidelines. J Dent Res 2014: 93: 8-18.

20. Lertpimonchai A, Rattanasiri S, Vallibhakara S A-O Attia J, Thakkinstian A. The association between oral hygiene and periodontitis: a systematic review and meta-analysis. Int Dent J 2017; 67: 332-343.

21. Macfarlane G J, Zheng T, Marshall J R et al. Alcohol, tobacco, diet and the risk of oral cancer: a pooled analysis of three case-control studies. Eur J Cancer B Oral Oncol 1995; 31: 181-187.

22. Office for Health Improvement and Disparities, Department of Health and Social Care, NHS England and NHS Improvement. Delivering better oral health: an evidence-based toolkit for prevention 4th Edition. Updated 9 November 2021. Available at https://www. gov.uk/government/publications/ delivering-betteroral-health-an-evidence-based-toolkit- for-prevention (accessed November 2021).

23. Sheiham $A$, Watt $R G$. The common risk factor approach: a rational basis for promoting oral health. Community Dent Oral Epidemiol 2000; 28: 399-406.

24. Singh A, Rouxel P, Watt R G, Tsakos G. Social inequalities in clustering of oral health related behaviours in a national sample of British adults. Prev Med 2013; 57: 102-106.

25. Sanders A E, Spencer A J, Slade G D. Evaluating the role of dental behaviour in oral health inequalities. Community Dent Oral Epidemiol 2006; 34: 71-79.

26. Sabbah W, Tsakos G, Sheiham A, Watt R G. The role of health-related behaviours in the socioeconomic disparities in oral health. Soc Sci Med 2009; 68: 298-303.

27. Public Health England. National Diet and Nutrition Survey: time trend and income analyses for Years 1 to 9. 2019. Available at https://www.gov.uk/government/ statistics/ndns-time-trend-and-income-analyses-foryears-1-to-9 (accessed February 2021).

28. Scientific Advisory Committee on Nutrition. Carbohydrates and Health. 2015. Available at https://assets.publishing service.gov.uk/government/uploads/ system/uploads/ attachment data/file/445503/SACN Carbohydrates and_Health.pdf (accessed February 2021). 
29. Public Health England. The relationship between dental caries and body mass index. Child level analysis. 2019. Available at https://assets.publishing.service.gov.uk/ government/uploads/system/uploads/attachment data/file/844121/BMI_dental_caries.pdf (accessed February 2021).

30. Public Health England. Wider Impacts of COVID-19 on Health (WICH) monitoring tool. 2021. Available at https://analytics.phe.gov.uk/apps/covid-19-indirecteffects/ (accessed February 2021).

31. Public Health England. The Public Health Burden of Alcohol and the Effectiveness and Cost-Effectiveness of Alcohol Control Policies: An evidence review. 2016. Available at https://assets.publishing.service.gov.uk/government/ uploads/system/uploads/attachment_data/file/733108/ alcohol_public_health_burden_evidence_review_ update_2018.pdf (accessed February 2021).

32. Public Health England. Monitoring alcohol consumption and harm during the COVID-19 pandemic. 2021. Available at https://assets.publishing.service.gov.uk/ government/uploads/system/uploads/attachment data/file/1002627/Alcohol_and_COVID_report.pdf (accessed November 2021).

33. NHS England. Issue 3, Preparedness letter for primary dental care - 25 March 2020. 2020. Available at https:// wokingham.moderngov.co.uk/documents/s43592/ Issue $\% 203 \%$ 20Preparedness\%20letter\%20for $\% 20$ primary\%20dental\%20care\%20-\%2025\%20March $\% 20$ 2020.pdf (accessed February 2021).

34. Dave M, Seoudi N, Coulthard P. Urgent dental care for patients during the COVID-19 pandemic. Lancet 2020; 395: 1257.

35. Watt R G. COVID-19 is an opportunity for reform in dentistry. Lancet 2020; 396: 462.

36. Healthwatch. What are people telling us: July to September 2020. 2020. Available at https://www. healthwatch.co.uk/report/2020-12-09/what-arepeople-telling-us-july-september-2020 (accessed February 2021).

37. Public Health England. Hospital tooth extractions of 0 to 19 year olds. 2019. Available at https://www.gov.uk/ government/publications/hospital-tooth-extractionsof-0-to-19-year-olds (accessed February 2021).

38. Broomhead T, Rodd H D, Baker $S$ R et al. A rapid review of variation in the use of dental general anaesthetics in children. Br Dent J 2020; 229: 31-39.

39. Zaitoun H, Kandiah P, Yesudian G, Rodd H. COVID-19: implications for paediatric dental general anaesthetic services. Fac Dent J 2020; 11: 114-119.

40. NHS England. Consultant led Referral to Treatment Waiting Times Data 2019-20. 2019. Available at https://www.england.nhs.uk/statistics/statisticalwork-areas/rtt-waiting-times/rtt-data-201920/\#Mar20 (accessed February 2021).

41. NHS England. Consultant led Referral to Treatment Waiting Times Data 2020-21. 2020. Available at https://www.england.nhs.uk/statistics/statisticalwork-areas/rtt-waiting-times/rtt-data-202021/\#Aug20 (accessed February 2021).
42. House of Commons Library. Effect of covid-19 on dental services. 2021. Available at https://commonslibrary. parliament.uk/research-briefings/cdp-2021-0001/ (accessed February 2021).

43. Okike I, Reid A, Woonsam K, Dickenson A. COVID-19 and the impact on child dental services in the UK. BMJ Paediatr Open 2021; DOI: 10.1136/bmjpo-2020-000853.

44. Goodwin M, Sanders C, Davies G, Walsh T, Pretty I A. Issues arising following a referral and subsequent wait for extraction under general anaesthetic: Impact on children. BMC Oral Health 2015; DOI: 10.1186/1472-6831-15-3.

45. Oral Health Foundation. State of Mouth Cancer UK Report 2018/2019. 2019. Available at https:// www.dentalhealth.org/Handlers/Download. ashx? IDMF=21dc592b-d4e7-4fb2-98a9-50f06bed71aa (accessed February 2021).

46. Public Health England. Oral cancer in England: A report on incidence, survival and mortality rates of oral cance in England, 2012 to 2016. 2020. Available at https:// assets.publishing.service.gov.uk/government/uploads/ system/uploads/attachment_data/file/891699/0ral_ cancer_report_170420.pdf (accessed February 2021).

47. Westgarth D. COVID-19 and Community Dental Services: The challenges ahead. BDJ In Pract 2020; 33: 14-19.

48. Mouth Cancer Foundation. Diagnosis of mouth cancer during COVID-19 pandemic 2020. Available at https://www.mouthcancerfoundation.org/news/ diagnosismouthcancerduringcovid19pandemic (accessed February 2021).

49. Westgarth D. Oral cancer: A ticking time bomb? BDJ In Pract 2020; 33: 14-18.

50. Sud A, Torr B, Jones M E et al. Effect of delays in the 2 weekwait cancer referral pathway during the COVID19 pandemic on cancer survival in the UK: a modelling study. Lancet Oncol 2020; 21: 1035-1044.

51. Public Health England. Improving oral health: A toolkit to support commissioning of supervised toothbrushing programmes in early years and school settings. 2016. Available at https://assets.publishing.service.gov.uk/ government/uploads/system/uploads/attachment_ data/file/574835/PHE_supervised_toothbrushing_ toolkit.pdf (accessed February 2021)

52. Office for National Statistics. Deaths involving COVID19 in the care sector, England and Wales: deaths occurring up to 12 June 2020 and registered up to 20 June 2020 (provisional). 2020. Available at https:// www.ons.gov.uk/peoplepopulationandcommunity/ birthsdeathsandmarriages/deaths/articles/deaths involvingcovid19inthecaresectorenglandandwales/ deathsoccurringupto12june2020andregisteredupto20j une2020provisional\#deaths-involvingcovid-19-amongcare-home-residents (accessed February 2021).

53. Care Quality Commission. Smiling matters: Oral health care in care homes. 2019. Available at https://www.cqc. org.uk/sites/default/files/20190624_smiling_matters_ full_report.pdf(accessed February 2021).

54. NHS England and NHS Improvement. The Framework for Enhanced Health in Care Homes. Version 2. 2020.
Available at https://www.england.nhs.uk/wp-content/ uploads/2020/03/the-framework-for-enhanced-healthin-care-homes-v2-0.pdf (accessed February 2021).

55. McKenna G, Janssens B, Srinivasan M, Brocklehurst P Tsakos G. Who is caring for the oral health of dependent institutionalised elderly during the COVID-19 pandemic? Gerodontology 2020; 37: 315-316.

56. NHS Information Centre. Service considerationsa report from the Adult Dental Health Survey 2009. 2011. Available at https://files.digital.nhs.uk/publicationimport/ pub01xxx/pub01086/adul-dent-heal-surv-summ-themthe6-2009-rep8.pdf (accessed March 2021).

57. World Health Organisation. Oral health: Achieving better oral health as part of the universal health coverage and noncommunicable disease agendas towards 2030. Report by the Director-General. 2020. Available at https://apps.who.int/gb/ebwha/pdf_files/ EB148/B148_8-en.pdf(accessed February 2021).

58. World Health Organisation Discussion Paper: Draft Global Strategy on Oral Health. 2021. Available at: https://www.who.int/publications/m/item/whodiscussion-paper-draft-global-strategy-on-oral-health (accessed November 2021).

59. Public Health England. Water fluoridation: health monitoring report for England 2018. 2018. Available at https://assets.publishing.service.gov.uk/government/ uploads/system/uploads/attachment_data/ file/692756/EXECUTIVE_SUMMARY_Water_ Fluoridation_Health_monitoring_report_for England_2018_DR.pdf (accessed February 2021).

60. Macpherson L M D, Anopa Y, Conway D I, McMahon A D. National Supervised Toothbrushing Program and Dental Decay in Scotland. J Dent Res 2013; 92: 109-113.

61. Institute for Fiscal Studies Deaton Review. Inequalities in education, skills, and incomes in the UK: The implications of the COVID-19 pandemic. 2021. Available at https://ifs.org.uk/inequality/inequalitiesin-education-skills-and-incomes-in-the-uk-theimplications-of-the-covid-19-pandemic/ (accessed May 2021).

62. The Kings Fund. The English local government public health reforms: an independent assessment. 2020. Available at https://www.kingsfund.org.uk/ publications/local-government-public-health-reforms (accessed April 2021).

63. European Public Health Association. European Public Health Association (EUPHA) and the Association of Schools of Public Health (ASPHER) to unite for strong leadership for public health. 2021. Available at https:// eupha.org/repository/advocacy/Statement\%20EUPHA ASPHER_Strong\%20leadership\%20for\%20public\%20 health.pdf (accessed May 2021).

64. Institute of Health Equity. Build back fairer: The COVID19 Marmot review. The pandemic, socioeconomic and health inequalities in England. 2020. Available at https://www.instituteofhealthequity.org/resourcesreports/build-back-fairer-the-covid-19-marmot-review/ build-back-fairer-the-covid-19-marmot-review-fullreport.pdf (accessed April 2021). or other third party material in this article are included in the article's Creative Commons licence, unless indicated otherwise in a credit line to the material. If material is not included in the article's Creative Commons licence and your intended use is not permitted by statutory regulation or exceeds the permitted use, you will need to obtain permission directly from the copyright holder. To view a copy of this licence, visit http://creativecommons.org/licenses/by/4.0 